\title{
Increasing the Organizational Influence of Corporate Consumer Affairs Departments
}

\begin{abstract}
Empirical research suggests that most corporate consumer affairs departments are not a part of the decision-making structure of their respective firms. The typical consumer affairs department appears to have little influence in management decisions that affect consumer satisfaction and welfare. As a result, it is of limited value for the consumer.

A reason for the isolation of consumer affairs from corporate decision making may be that the department's contribution to the firm's welfare is not well understood. By showing a significant contribution to company sales, the consumer affairs department would be in a position to gain influence in the profit-seeking organization. The article identifies the relationship between sales and complaint management within a marketing framework and develops objectives for complaint management that maximize the consumer affairs department's contribution to sales thereby enhancing the power base of the department within the business organization.
\end{abstract}

The past decade witnessed a rapid increase in the number of business firms with internal consumer affairs departments. Almost all major U.S. corporations competing in consumer markets now have a formalized organizational unit for the handling of consumer affairs. Ideally, these units should be vehicles for consumer influence in management decision-making and provide consumers with a direct channel for information and redress. They should also provide the firm with an effective early warning system concerning consumer problems and discontent $[11,16,17,21,26]$. In reality, however, empirical research has pointed out that most consumer affairs departments perform a rather isolated service $[4,10,14,17]$. The typical department is not integrated within the decision-making structure of its organization and has little influence in such matters as advertising, product quality, pricing, and marketing.

Claes Fornell is an Associate Professor of Marketing at the Graduate School of Business Administration, The University of Michigan, Ann Arbor, Michigan.

The author acknowledges the helpful comments of Philip Kotler and Louis W. Stern at Northwestern University and C. A. Knook, Unilever, Ltd., England. 
One likely reason for the limited consumer influence via the consumer affairs department is that the department's potential contribution to overall corporate objectives is not well understood. The relationship between profitability and the performance of corporate consumer affairs has not been examined and is often subject to question [11]. This is especially evident in an inflation-ridden economy where few operations within the firm escape increased cost justification pressures.

A familiar finding in the organizational behavior literature is that those who control the objectives and operations of a firm wield the most power. Generally speaking, the degree of power possessed by a particular organizational unit is proportional to its contribution to the well being (or profitability) of the organization. For example, the ability to cope with uncertainty $[5,13,31]$ and control over critical resources [27] are two important bases of power. In order for a consumer affairs unit to acquire influence in corporate decision making, it is necessary for it to hold or obtain power bases that can be exploited in a manner consistent with both consumer interests and company profitability.

While the responsibilities, design, and organizational positioning of consumer affairs departments vary across corporations, consumer complaint processing is a central activity for most of them. The high frequency of reported consumer problems in the marketplace [3] makes the firm's response to consumer complaints important not only for compensating individual consumers, but, as will be demonstrated in this article, for improving company sales performance as well. It will be argued that the power bases available to consumer affairs relate, both directly and indirectly, to the control of one of the most critical resources of any organization-the customers. By defining the relationship between complaint management and sales performance, it is possible for the consumer affairs department not only to justify its existence in the profit-seeking organization but also to enhance its influence. Accordingly, this article will develop objectives for complaint management that maximize its sales contribution. In other words, it will be shown that the profit-seeking firm stands to gain in sales by giving its consumer affairs department increased responsibilities and more influence in marketing matters. 


\section{COMPLAINT MANAGEMENT DEFINED}

Efficiency in complaint handling usually refers to the procedures involved and the steps taken to ensure rapid turnover of complaints, accurate and fair responses to consumers, and low complaintprocessing costs. Reductions in the ratio of complaints to products sold are seen as favorable and complaint decrease is a common objective.

Complaint management is broader in scope. It differs from complaint handling in that it incorporates objectives that are explicitly linked to marketing and sales performance. Moreover, complaint management, as will be seen, does not automatically subscribe to the notion of complaint reduction as an objective, without first examining the firm's opportunity costs.

Voiced complaints are but one expression of dissatisfaction. Complaint management, as opposed to complaint handling, deals with the whole spectrum of consumer dissatisfaction responses regardless of whether they are voiced or not. It operates to minimize the harmful effects of consumer dissatisfaction on the firm, to analyze and address the marketing opportunities presented by consumer problems and to reduce consumer dissatisfaction.

With extended responsibilities and functions there are also increased operating costs. Just because good complaint handling promotes brand loyalty and positive word-of-mouth communication is not sufficient reason to justify the increased costs incurred by complaint management. Instead, complaint management should be expected to justify its existence as a managerial function within a profit-seeking organization in terms of its contribution to sales and profits. Towards that end, we will develop objectives of complaint management that augment the relationship between sales and complaint processing in such a manner that the long-term sales contribution is maximized. Under these circumstances, the organizational influence of consumer affairs is likely to be enhanced.

\section{METHOD: A REDUCTIONIST APPROACH}

Predicting and evaluating sales responses to marketing programs are essential parts of management theory and practice which have received considerable attention in the research literature. Among the 
difficulties that continue to plague attempts to specify the results of marketing efforts are the isolation of effects and the indirect relationship to sales presented by many marketing activities.

While behavioral scientists have approached the problem of evaluating the effectiveness of marketing programs (and advertising in particular) by partitioning the consumer decision process into micro components or intervening variables (e.g., awareness, cognition and attitude), the sales variable, which is typically dealt with at a more aggregated level, has not been subject to similar analysis. Even when aggregation is confined to the individual brand level, the sales variable remains a crude summary statistic of consumer purchase behavior.

As will be shown in this article, it is possible to partition the sales variable into more meaningful components of consumer behavior, without resorting to non-behavioral constructs. Identification of these components will facilitate construction of sales response models and, in this particular case, help determine the potential sales contribution of complaint management.

In the same way as the sales variable can be viewed as a whole or a set that can be divided into parts or components, the consumer complaint variable can be thought of as a part of a dissatisfaction set. The method to be employed here belongs to the reductionist model of analysis in that it approaches the sales-complaint management relationship by partitioning the sets into smaller parts in order to find identical or related elements. If one set contains elements that are present in the other set, the magnitude of the communality defines the potential sales contribution of complaint management. If some parts are identical, while others are distinct, analysis turns to the within-set relationships between common and distinct parts in the dissatisfaction variable.

Specifically, the methodology involves the following steps:

1. Identify sales variable components.

2. Identify consumer dissatisfaction variable components.

3. Specify the intersection and relationship between the above variables.

Many marketing activities are assumed to have an indirect or more long-term bearing on sales. Marketing research for purposes of aiding management decision-making is in this category. Similarly, 
complaint management, in its handling of consumer communications, is in a position to extract potentially valuable information on consumer problems. The value of this information for long-term sales performance is largely determined by its power to help identify market opportunities and eliminate specific origins of consumer dissatisfaction. Consequently, the indirect complaint managementto-sales relationship will be examined in the following steps:

1. Specify the information necessary for dissatisfaction elimination.

2. Specify the information necessary for market opportunity identification.

3. Examine each dissatisfaction variable component in terms of its information value.

Assuming that consumer dissatisfaction response can be influenced by management strategy, the objectives of complaint management will be determined by arranging the dissatisfaction variable components so that both direct sales and information value are maximized. Following the identification of sales components in the next section, we turn to the identification of consumer dissatisfaction components and the intersection between these two sets of variables.

\section{MARKET TRAFFIC AND SALES COMPONENTS}

Development of successful marketing and sales strategy depends heavily upon the firm's ability to identify and influence the flows of customers into and out of its franchise and in and out of the market. In the context of this analysis, these flows are termed market traffic. They include the entering of new customers, brand shifting or change of patronage, and product class transfers. Changes in the rate of purchase are equivalent to changes in the speed of traffic. It is this traffic that firms seek to control, for it is the ultimate determinant of growth, stagnation and decline.

To illustrate how market traffic affects the sales performance of an individual company, let $\mathrm{a}, \mathrm{b}$, and $\mathrm{c}$ be competing single-brand firms in market $M$. Let $Z$ denote all other markets and $V$ indicate the speed of traffic within $M$. Figure 1 illustrates the flows that constitute the traffic in market $M$, and some possible strategies of demand stimulation for company (brand) a.

Firms with substantial shares of growing markets may elect to 
FIGURE 1

Market Traffic.

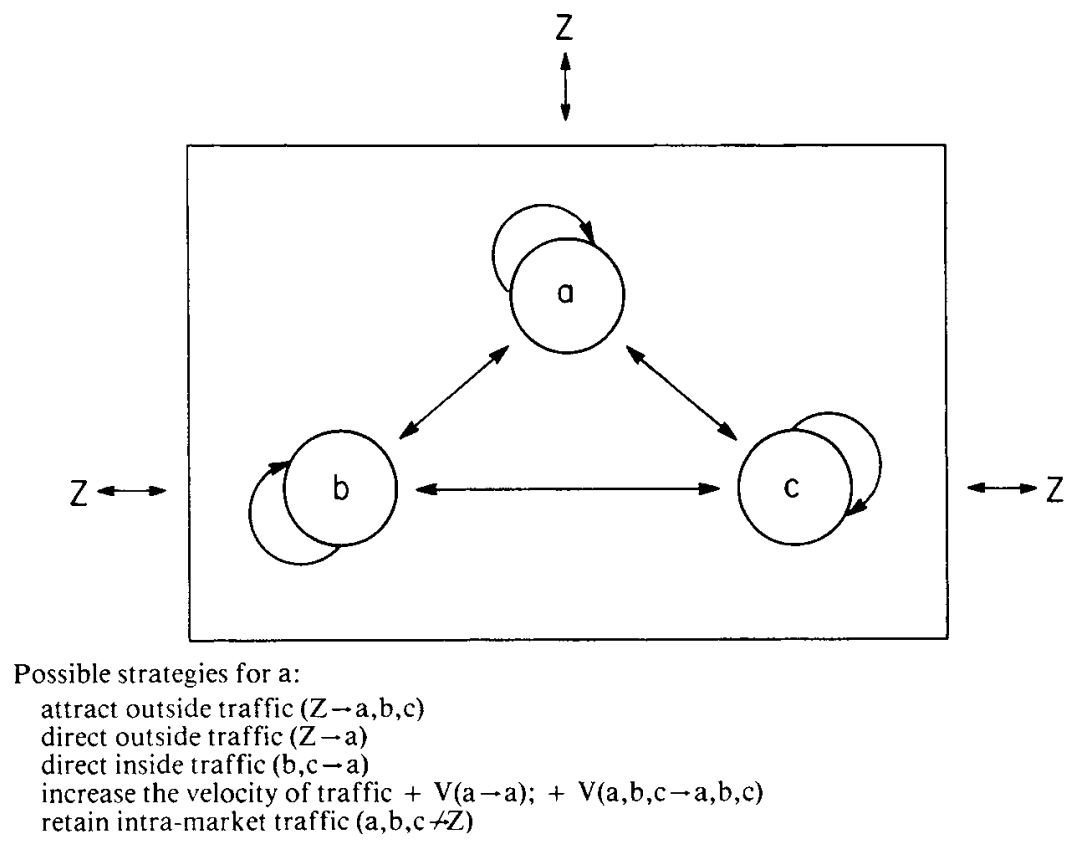

concentrate marketing efforts toward the promotion of product category rather than individual brand, and thus stimulate primary demand $(Z \rightarrow a, b, c)$. In stagnating markets, competition for market shares becomes more intense and primary focus is often shifted to the capture of customers at the expense of competing organizations. More resources are allocated to stimulate selective demand $(Z \rightarrow a)$, to encourage brand switching $(b, c \rightarrow a)$ and brand loyalty $(a \rightarrow a)$, to increase brand usage $[+\Delta \mathrm{V}(\mathrm{a} \rightarrow \mathrm{a})]$, and to prevent product class transfers $(a, b, c+Z)$.

The sales performance of an individual company is determined by the market traffic it generates. Consequently, the components relevant to the sales performance of company a can be written in set theory notation as:

$$
\Omega_{M a}=[(a \leftrightarrow a) ;(b, c \leftrightarrow a) ;(Z \leftrightarrow a)]
$$

Compared to the more traditional and aggregate view of the sales variable, the market traffic conceptualization offers some distinct 
advantages: It is dynamic and describes the sources of sales performance in a managerial strategy framework. The relationship between sales and marketing variables is made explicit in the formulation of strategies to direct, attract, restrict, and retain market traffic as well as increase the speed of traffic.

Using the market traffic terminology, the criteria for determining direct (short-term) and indirect (long-term) sales contribution of an organizational activity or unit are:

1. Its capability for controlling market traffic. (direct contribution)

2. Its capability for assisting in market traffic control by furnishing valuable information. (indirect contribution)

In order to specify the intersection of sales and consumer dissatisfaction response and start developing objectives against which the criteria above will be measured, the next task is to identify the components of dissatisfaction response.

\section{MARKET TRAFFIC AND CONSUMER DISSATISFACTION}

From the firm's point of view, the purpose of complaint management is to handle consumer dissatisfactions in such a way that their negative and harmful effects on the firm are minimized and its opportunities for growth and competitive advantage identified.

It seems reasonable to assume that almost all consumer complaints have their roots in some experienced dissatisfaction or problem. Complaining is one of several possible consumer reactions to problems arising from satisfaction blockage. All such problems, however, cannot be traced to product malfunctions and breakdowns or to predatory or fraudulent business conduct. As illustrated in one of the few major empirical consumer dissatisfaction studies [3, see also 28], many consumer grievances can best be explained by ignorance, misunderstandings or disagreements.

While certainly relevant to complaint management, it is not necessary for the purposes of this paper to go into the details of the psychosocial processes leading to dissatisfaction. It is the responses to the frustration caused by it and their implications for the firm that are of primary interest.

The consumer's dissatisfaction with a product, service, or other elements in a firm's marketing mix can be expressed in a variety of 
ways, ranging from organized boycotts to complete behavioral inaction. It is useful to consider three categories of consumer dissatisfaction response: market action, complaining and inaction. Market action refers to brand switching, purchase termination, and reduction in purchase rate. Complaints can be directed at a firm or registered with a third party. Inaction, of course, simply means that the dissatisfied consumer does nothing to resolve the problem.

Let $\Omega_{D a}$ denote the set of possible consumer dissatisfaction responses that relate to firm (brand) a. With the notation previously introduced, the distinct dissatisfaction responses are:

$$
\Omega_{D a}=\left[-\Delta \mathrm{V}(\mathrm{a} \rightarrow \mathrm{a}) ;(\mathrm{Z}-\mathrm{a}) ;(\mathrm{b}, \mathrm{c} \leftarrow \mathrm{a}) ;\left(\mathrm{C}_{a}\right) ;\left(\mathrm{C}_{r}\right) ;(\mathrm{I})\right]
$$

where $-\Delta V(a \rightarrow a)=$ reduction in purchase rate

$$
\begin{aligned}
(\mathrm{Z}-\mathrm{a})= & \text { purchase termination or product class } \\
& \text { transfers } \\
(\mathrm{b}, \mathrm{c}-\mathrm{a})= & \text { adverse brand shifting } \\
\left(\mathrm{C}_{a}\right)= & \text { complaint directed at } \mathrm{a} \\
\left(\mathrm{C}_{r}\right)= & \text { complaint via third party or collective } \\
& \text { consumer protest } \\
(\mathrm{I})= & \text { inaction }=(\mathrm{a} \rightarrow \mathrm{a})
\end{aligned}
$$

$\Omega_{D a}$ includes all relevant components of consumer dissatisfaction response. Since inaction is defined as a "response," $\Omega_{D a}$ represents the total amount of dissatisfaction directed at company (brand) a, regardless of whether or not the dissatisfaction is overtly expressed. While there may be other ways of categorization, the components in $\Omega_{D a}$ are exhaustive.

Having defined both sales and consumer dissatisfaction response in terms of their parts or components, it is clear that the elements shared by the two sets identify the direct relationship between complaint management and sales:

$$
\Omega_{M a} \cap \Omega_{D a}=-\Delta V(a \rightarrow a) \operatorname{UV}(Z-a) U V(b, c,-a)
$$

where $\mathrm{V}$ (velocity) is the average purchase rate over a given time period. The intersection of the dissatisfaction and market traffic sets thus defines company (brand) a's revenue loss. The cost of consumer market action is equal to the product unit contribution multiplied by 
the traffic lost. As will be shown later, this cost can be substantial, particularly for firms that sell non-durables and rely heavily on repeat purchase.

If direct sales are to be maximized, it is obvious that complaint management should, if possible, seek to dissuade dissatisfied consumers from taking market action. This can only be done by responding to consumer complaints to the satisfaction of the complainants, thereby making consumer market actions superfluous. This is not to say that all complaints can be handled in a manner that provides complete satisfaction, but that it is in the best interests of both parties to strive toward that end. For successful complaint management minimizes sales losses due to consumer dissatisfaction and reduces the consumer's cost (in terms of money, time, effort and risk) as well. Certainly, most of these costs will increase if the dissatisfied consumer is forced to go beyond the company in order to obtain redress.

However, our analysis of the direct sales contribution does not provide guidance for determining the cost/benefits of having dissatisfaction expressed in the form of complaints versus not having it expressed at all. In order to determine where to channel consumer dissatisfaction so as to maximize long-term sales performance, the firm must look beyond the direct short-term sales contribution. The threats and information value of each dissatisfaction response will also have to be evaluated. The information value of the various responses determines the indirect consideration of complaint management.

\section{THE INDIRECT-COMPLAINT MANAGEMENT-TO-SALES CONTRIBUTION}

Although the very existence of consumer dissatisfaction implies market imperfections, it also presents the individual firm with an opportunity for improvement and, depending upon the circumstances, a chance to enhance competitive position. In order to effectively handle consumer dissatisfaction and to be able to identify market opportunities that may follow, the firm needs information on the following:

1. The magnitude of dissatisfaction, to determine whether the problem should be attacked on an individual consumer basis or on an aggregate (market) basis.

2. The nature of the problem, to determine how it should be 
categorized and understood (e.g., does it refer to the shopping experience, the transaction, or a particular feature of the product?).

3. The distribution of the dissatisfaction, to determine the potential market targets for corrective action.

4. The importance of the problem as perceived by the consumer, to determine urgency of action.

5. The causes of the dissatisfaction, to determine what actions will be most effective in resolving the problem.

\section{Consumer Inaction}

With consumer inaction, no action is taken to resolve the problem by the consumer or the firm. In the long run, however, it is not certain that consumers will continue to suppress dissatisfaction. Inaction may turn to action if consumers become aware of available routes of redress or if they become more motivated to release their frustrations. Several studies suggest that many dissatisfied consumers fail to communicate their problems for remedial action, but may engage in negative word-of-mouth communications to warn other consumers $[7,8,20,25,30,32]$.

The dissatisfied consumer's decision to do nothing has no immediate effect on the market traffic. It does, however, make the firm more vulnerable to competitive inroads since the firm remains unaware of the existence of consumers' dissatisfaction. Should the nature of competitive offerings change, there is always the risk that the sales performance of the firm (brand) will be impaired.

\section{Consumer Market Action}

Brand shifting, product class transfers, purchase termination, and purchase rate reduction are behavioral responses to dissatisfaction. These market actions are non-verbal communications which may be picked up by the firm as sales reductions. But it is by no means certain that these changes in market traffic will be correctly perceived. As with all statistics, there is the problem of pooling and aggregating data. Consider two groups of consumers, one very pleased and the other very displeased, with a firm and its products. Increased purchases and the effects of positive word-of-mouth communications generated by the first group may well cancel the negative behavioral 
actions of the second group. For durable products, there is an additional drawback in relying on sales statistics to discover consumer dissatisfaction, i.e., the slow transmission of information.

Depending on the rate and extent of shifts in market traffic, the consumer's decision to abandon the firm may give some indication of the magnitude and importance of the dissatisfaction. Depending on how sales statistics are compiled, there may also be information on the distribution of the dissatisfaction. It is less likely that consumer market actions alone can furnish much information on the nature, let alone the origin, of the problem. In isolation, without other sources of data, the information provided by sales statistics is weak. It indicates the magnitude and change in sales development, but not much more.

\section{Consumer Complaints}

Whereas consumer inaction suppresses communication between the consumer and the firm and consumer market action is a communication via sales statistics, consumer complaints are verbal communications. As mentioned, there are two categories of complaints: one directed toward the complainees, the other toward a third party such as a governmental or legal agency, a media ombudsman, or a consumer organization which uses a direct action approach (e.g., collective protests or demonstrations).

Almost all complaints via third parties are preceded by unsuccessful attempts to obtain remedy from a manufacturer, retailer, or service outlet. In an analysis of consumer calls to a "Hot Line," it was found that 93 percent of the complainants had first contacted the complainee [9]. Similar results have been reported in a study of consumer complaints to a newspaper ombudsman in Canada [12]. Unless the costs of complaint processing are deemed so high that they offset the adverse effects of potential negative publicity, wordof-mouth communications and legal action, firms seek to avoid third-party intervention. The following discussion will be limited to complaints directed toward complainees.

Contrary to the communication in market actions, complaint communications provide evidence, albeit often conjectural, on the nature and causes of dissatisfaction. While market action communication is inherently monological, complaint communication is 
essentially dialogical. Market actions taken by dissatisfied consumers describe how the firm becomes a victim of communication rather than how communication is used as a means for constructive information exchange. Even though complaint data have been found to be biased in favor of certain problems and certain consumer groups $[3,8]$, they can probably provide valuable starting points for suggestions and hypotheses to guide the search for causes and solutions. If used properly, it seems likely that they can also help to amplify marketing research findings and as a means for validity and reliability assessment. For example, a food processing company's marketing research indicated that consumers did not want artificial colors, artificial flavors, flavor enhancers or preservatives in certain foods. Unsolicited consumer complaints supported these findings and suggested that many consumers wanted to return to the basics in food. This does not imply, however, that complaints can be held responsible for complete inventories of consumer concerns.

The cost of complaint processing, including dissatisfaction analysis and consumer compensation, constitutes the direct costs of consumer verbal action. The threats pertain to the possible consequences of failing to close complaints to the satisfaction of complainants (e.g., negative publicity, legal action, market action or boycotts).

\section{Information Value: Conclusion}

The comparison of dissatisfaction responses suggests that consumer market actions are more costly for the organization than are other responses. Not only are they harmful in their redirection of market traffic away from the firm, but they contribute little information for managerial guidance. Statistics on sales decline indicate seller problems; the language is couched in numbers and figures. Consumer complaints indicate individual consumer problems; the grievances are expressed in everyday language. Aggregate consumer problems define market problems. A marketing problem, finally, is a consumer problem that is relevant to the purposes and resources of the firm and is shared by a sufficiently large number of consumers to make its resolution economically feasible. Consequently, this is how a firm with dwindling sales will have to define its problem before corrective action is taken. As for consumer inaction, it is the least 
costly response-especially in the short run-but it generates no information at all.

\section{SPECIFYING OBJECTIVES}

Having described the properties of the different consumer dissatisfaction responses in terms of their costs, threats, and information value, the objectives of complaint management can be developed by weighing the costs and benefits of each response.

\section{Objective One: Complaint Maximization}

Assuming that: (1) firm (brand) a is operating in a competitive environment; (2) the zero direct costs of consumer inaction are outweighed by the danger in ignoring consumer dissatisfaction; (3) management strategy can be developed to influence consumer dissatisfaction response; and (4) the origin of each specific dissatisfaction will eventually be detected and removed, the first objective of complaint managment can be written:

$$
\operatorname{MAX}_{(b, c-a) U-\Delta V(a \rightarrow a) U(Z \leftarrow a) U(I)}
$$

Since complaints to third parties and consumer protest via demonstration or collective boycotts are almost always preceded by direct complaints, the $\mathrm{C}_{r}$ term can be ignored at the moment.

The notion of complaint maximization as expressed in Equation 4 is quite contrary to popular belief and ordinary practice. More commonly companies attempt to minimize the number of complaints. Complaint maximization derives from the syllogistic-like reasoning that there is a finite and identifiable set of consumer responses to dissatisfaction; and that complaints, under most circumstances, are less harmful and more useful than other responses. Therefore, complaints should be maximized relative to other responses.

As illustrated in Figure 2, the pursual of complaint reduction or complaint minimization may reduce complaints while simultaneously increasing other expression of consumer dissatisfaction. The simplest way to achieve a reduction in complaints would be to "close" the C-entry in Figure 2, or to make it difficult, timely, and unpleasant for consumers to complain. For example, some airlines 
FIGURE 2

Consumer Responses to Dissatisfaction.

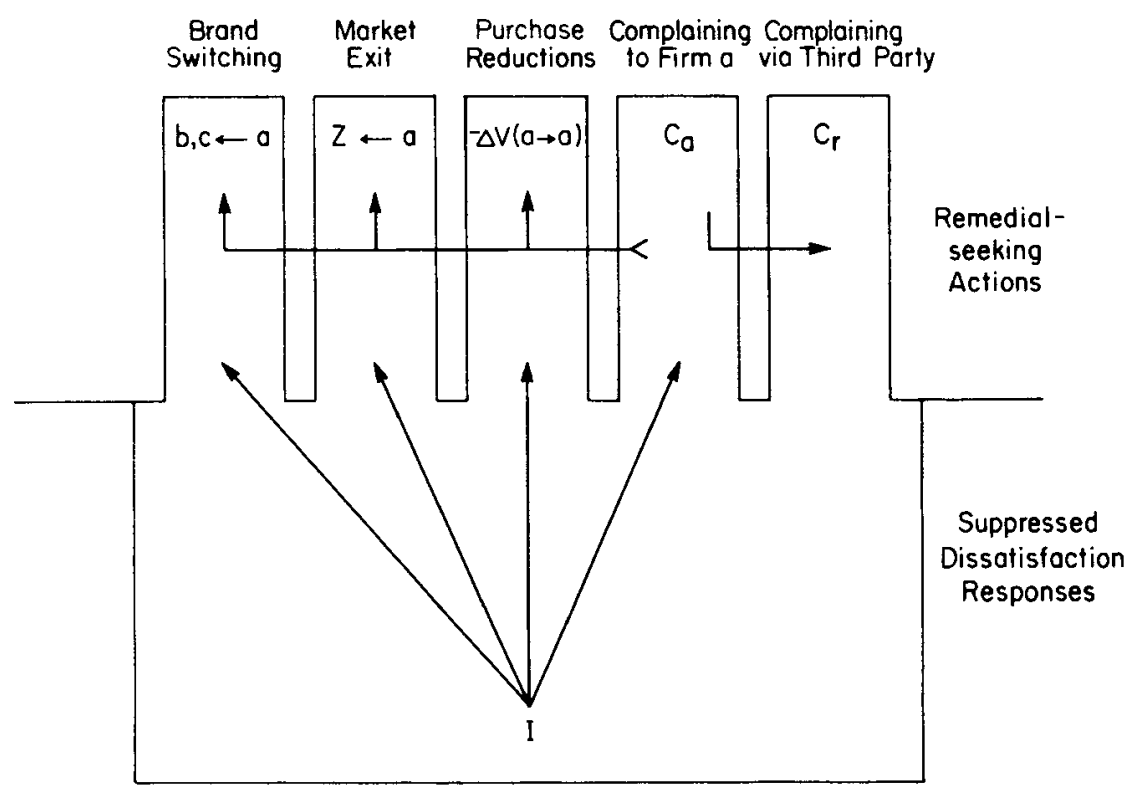

are no longer making complaint forms readily accessible for their passengers. Forms used to be placed in the seat pocket of each flight, but because of the large volume of complaints that was generated this practice was discontinued. Apparently, little attention was paid to what the dissatisfied passenger might do when the complaint outlet became less convenient. Similar examples can be found in other industries. A major oil company recently disconnected a tollfree telephone number which had been available for consumers to use for registering complaints. The reason for the removal was that the company was receiving too many calls over the line and was not willing to pay the staff costs associated with it. Interestingly enough, complaints to the company's motor club (which still offers a toll-free number) have since increased. Regardless of whether or not complaining is actually dissuaded, complaints would certainly not be welcome in a firm which interprets their frequency as a gauge of marketing or product performance. As a consequence, a company 
policy aimed at reducing the number of consumer complaints runs the risk of encouraging consumers to seek other ways to obtain remedy and satisfaction.

An additional drawback of complaint minimization as an objective is that as complaints are reduced, so is information about consumer problems. Unless one can be certain that complaint reduction is equivalent to dissatisfaction reduction, the frequency of complaints is not an appropriate measure of success or failure. Complaint maximization, on the other hand, operates to increase information by channeling dissatisfaction into complaint responses.

\section{Objective Two: Complainant Satisfaction}

Extending the analysis from single to multiple dissatisfaction responses, note that complaining via a third party $\left(\mathrm{C}_{r}\right.$ in Figure 2$)$ is a secondary response (reflecting the fact that almost all dissatisfied consumers contact the complainee before calling in a third party or engaging in collective demonstrations) and that other responses can be both primary and secondary. Allowing for the possibility of multiple responses, complaint management should attempt to minimize the probability that the complainant takes other actions. Hence, complaint management should encourage dissatisfied consumers to contact the company before they contemplate additional actions. The objective, once a complaint has been received, is to resolve the problem in such a way that the complainant will consider other actions to be superfluous.

\section{Revenue Potential from Objectives One and Two}

The maximum revenue to be gained from implementing the proposed objectives is given by the intersection between complaint management and sales (Equation 3). To find out the magnitude of this potential revenue, we must determine the parameters of the equation.

Several studies have sought to estimate the proportion of complaints relative to market actions and inaction. While there is general agreement that the dissatisfaction response is influenced by product category, severity of problem, and socioeconomic status of consumer, the evidence as to the relative frequency of the various responses is conflicting. 
In a survey regarding grocery store items, the A. C. Nielsen Company [22] found that 19 percent of the dissatisfied consumers exited the market and 25 percent shifted to another brand. For the same product category, Best and Andreasen [3] reported 11 percent combined exits and brand shiftings. For consumer services, Day and Bodur [7], in their survey of consumers in a midwestern city, found market actions to be the most common dissatisfaction response affecting 46.4 percent of their sample, while the corresponding figure in Best and Andreasen's study was 6.4 percent.

Working with Nielsen data for an estimated 2,000,000 dissatisfied customers, where market actions amounted to 38 percent, and where actual annual purchase frequency per customer was assumed to be 10 units, Kendall and Russ [17] showed that the potential revenue (opportunity loss) for a food processing company with 40,000 complaints was $7,600,000$ units of sales per year.

Assuming that 20 percent of the dissatisfied consumers decided to reduce their annual purchase rate from 10 to 8 units, and that 15 percent of those who took market actions abandoned the market, Equation 3 gives the potential revenue from complaint maximization and complainant satisfaction:

$$
\begin{aligned}
& -\Delta V(a \rightarrow a)+(Z-a)+(b, c-a)=2(400,000)+ \\
& 10(114,000)+10(646,000)=8,400,000 \text { units of sales }
\end{aligned}
$$

Applying Best and Andreasen's [3] findings of 11 percent market actions and 16.5 percent complaints to the same company with the same assumptions regarding purchase rate, the number of dissatisfied consumers is estimated as 242,424 , and the potential revenue drops to 363,636 units per year. The vast discrepancies between the estimates derived from these studies suggest that individual companies will have to rely on their own estimates of dissatisfaction and dissatisfaction response.

Objective Three: Identification of Problems and Opportunities

While complaint maximization and complainant satisfaction have a direct bearing on market traffic, they are also defensive in character. Both take consumer dissatisfaction as given. But consumer dissatisfaction is not a static phenomenon, nor is its occurrence inde- 
pendent of organizational behavior. Determining the magnitude, nature, distribution, importance and causes of consumer dissatisfaction, and assisting in detecting marketing opportunities among unresolved consumer problems are a third task of complaint management.

While one can find different conceptualizations of consumer dissatisfaction in the literature, there is general agreement that dissatisfaction is a function of violated expectancy and that the probability of dissatisfaction increases with the perceived degree of discrepancy between actual outcomes and expected consequences $[1,2,6,15,18$, 23]. In this light, it might seem natural to express a third objective of complaint management as the minimization of the expectancy-product (or service) performance gap. But this would be too simplistic and narrow a formulation. While it acknowledges that dissatisfaction is a relative construct, it restricts relativity to expectations and ignores the fact that consumer evaluation is also affected by such factors as post-purchase brand comparisons, post-purchase peer group influences, product unavailability, and need for variety and novelty.

Although not conclusive, empirical research seems to support the assimilation-contrast model of consumer post-purchase evaluation $[1,24]$. When the expectancy-product performance gap is minor, evaluation of the product is assimilated toward expectations; when discrepancy is substantial, evaluation takes a downturn and is contrasted to expectations. If indeed consumer product evaluation has an inverted U-shape, as implied by the assimilation-contrast model, optimal satisfaction (product evaluation) is achieved even though consumer expectancy is somewhat inflated relative to "actual" product performance. For this reason, it seems that the benefits for complaint management in following the expectation-evaluation conceptualization in eliminating dissatisfaction by matching consumer expectation and product performance would be equivocal at best.

For growth-oriented firms, it is not enough to retain and to restrict intra-market traffic. Strategies for growth are needed to address the problems engendered by consumer dissatisfaction. Different levels of dissatisfaction magnitude pose different problems and require different organizational responses. Consider the following four levels in Table 1. 
TABLE 1

Four Magnitudes of Consumer Dissatisfaction and Organizational Response.

\begin{tabular}{|c|c|}
\hline PROBLEM MAGNITUDE & ORGANIZATIONAL RESPONSE \\
\hline $\begin{array}{l}\text { (1) Unique dissatisfaction } \\
\text { (2) Infrequent dissatisfaction } \\
\text { (3) Relatively frequent dissatisfaction } \\
\text { (4) Market dissatisfaction }\end{array}$ & $\begin{array}{l}\text { Case-by-case complaint handling } \\
\text { Standardized complaint handling } \\
\text { Segment opportunity } \\
\text { Product improvement/New product } \\
\text { development }\end{array}$ \\
\hline
\end{tabular}

First, there may be unique consumer problems (1). These occur only once and need ad hoc tailor-made responses. However, for cases in which small numbers of consumers are facing identical problems (2), it is probably better to standardize the complaint response. Although the problem is recurring, it does not affect enough consumers to warrant action at the aggregate level (i.e., a change in the product or its marketing). As the magnitude of dissatisfaction is increased, there could be an opportunity for market segmentation (3). As long as the dissatisfaction is limited to a minority of the customers it would be risky to alter or discontinue aspects of marketing unless one was certain of a positive reaction from the majority of the customers. A possible solution to this dilemma is offered by segmentation in the form of brand extension and different marketing programs to different customers. Finally, if the magnitude of dissatisfaction is close to 100 percent of the consumers (4), the inability or failure of consumers to take market action is the only reason that the firm is still in business. Either the firm is operating under conditions of monopoly or competing firms face identical unresolved problems. The organization that is able to break the monopoly or is first to offer a satisfactory solution will gain substantial market traffic and competitive advantage.

For some companies, particularly those which sell food products and other non-durable, low-cost items, the per-case cost of complaint processing may exceed product contribution to overhead. This does not mean that the idea of complaint maximization should be abandoned. But it does put more pressure on complaint management to swiftly identify the type of dissatisfaction directed at the firm so that corrective action can quickly be put into effect. Rapid discovery of consumer and market problems so that responses can be standardized, the opportunities exploited, and the threats curbed, also leads to reduced consumer dissatisfaction and a lowering of the 
number of complaints. However, when the problems identified cannot be satisfactorily resolved or when the firm needs time to find and implement a solution, it may be necessary, from a profitability perspective, to compromise the objective of complaint maximization.

\section{ADDITIONAL CONSIDERATIONS}

There are some conditions under which a consumer affairs department may not be able to pursue complaint maximization. For example, an organization operating in a stable environment offering consumer necessities while enjoying absolute monopoly may be able to discard consumer criticism without jeopardizing sales. Whether it also enjoys immunity to public opinion is, of course, another matter.

The multi-brand company may be more interested in maximizing market traffic among its various brands than in maximizing complaints. This strategy may be effective when dissatisfaction is caused by monotony in brand usage, which can be eliminated by offering variety. It assumes that the dissatisfaction is brand specific with no carry-over effects on the company as a whole.

The viability of complaint maximization also depends on the information available in addition to complaints and market actions. Strong arguments for developing better quality data on consumer dissatisfaction through survey research have been presented by a number of researchers $[1,3,6,19,29,32]$. They base their recommendations on the observation that only a fraction of consumer concerns is voiced in the form of complaints, and that complaint data, as a result, are afflicted with substantial shortcomings and serious bias. While this argument does not oppose the objectives of complaint maximization and prevention of multiple dissatisfaction responses, it questions the capability of complaint management to identify the true scope of consumer problems. It is paradoxical, then, that a byproduct of successful complaint maximization would be the elimination of the biases and shortcomings of complaint data. Although 100 percent implementation may not be realistic, it is possible that the larger the proportion of dissatisfied consumers complaint management is able to attract, the less biased and the more comprehensive the information it will generate.

Not until we have seen the effects of complaint maximization in operation can the issue of survey research versus complaint data be resolved. From a communications perspective, complaining and sur- 
vey research have few characteristics in common. In complaining, the consumer takes the initiative, develops a message, and selects a channel and intended receiver. The consumer (sender) controls the major aspects of the communication. In surveys, the organization (receiver) is in control. As has been shown elsewhere [10], complaints and surveys have different biases: where one is weak, the other is strong. Consequently, there is a good case for combining the two.

\section{SUMMARY}

Ample empirical evidence suggests that most corporate consumer affairs departments are excluded from marketing decision-making. As a result, these departments cannot provide much consumer input for marketing decisions. A likely reason for their organizational isolation is that the consumer affairs contribution to the profitability of the company is not well understood. One way to strengthen the consumer voice, via consumer affairs departments, would be to demonstrate the impact of consumer complaint management on company sales.

If it can be shown that complaint management has a significant effect on sales, it would be easier for a consumer affairs department to justify its corporate existence in terms of profitability, and to enhance its status and influence in decisions that affect consumer satisfaction and welfare. Accordingly, it was the purpose of this article to specify analytically the relationship between complaint management and sales and, subsequently, to derive objectives for complaint management that would maximize the relationship. The assumption was that the consumer voice has a better chance of being heard throughout a company if it is equipped with a strong linkage to company sales performance. That linkage was defined as the opportunity cost of losing a customer (i.e., if the dissatisfied consumer, instead of complaining, takes some form of market action). Brand switching, market exit, patronage change, and purchase rate reduction are all market actions that have a direct and adverse effect on sales. Complaining, on the other hand, has by itself no such effect. Instead, it affects profitability in two ways. First, since it has both fixed and variable costs, total costs are increased. Thus, there is a negative effect on profit. Second, to the extent that complaint management is successful in providing redress for individual consumers, customer 
loss is prevented. In this sense, complaint management has a positive effect on profit in terms of repeat buying. If the cost of complaint processing is less than the cost of losing a customer, it would be in the best interests of the firm to funnel consumer dissatisfaction into complaints. Failure to provide this outlet forces dissatisfied consumers to take their case elsewhere. To avoid this possibility, the following objectives for complaint management were derived:

1. Maximize consumer complaints relative to other consumer dissatisfaction responses.

2. Provide complainants with satisfactory remedy on an individual basis.

3. Identify market opportunities and problems on an aggregated basis.

Successful pursual of the first objective implies that the dissatisfied consumer contacts the firm before taking other actions. The second objective is geared towards the resolution of individual consumer problems in such a way that other consumer actions become unnecessary. Following the third objective, collective consumer problems are addressed in order to avoid future dissatisfaction.

These objectives are difficult to meet. Little is known about the factors that determine consumer response to dissatisfaction and perhaps even less about how to identify collective problems from complaint data. Empirical research on these issues is needed. However, by progressing towards the proposed objectives (as opposed to complaint minimization), both business firms and consumers stand to gain. The consumer affairs department will provide the consumers with a direct two-way communication channel to firms. As a result of its demonstrated impact on sales and profits, consumer affairs will be in a better position to influence marketing decisions in the company and consumer grievances will be taken more seriously. Finally, it should be emphasized that complaint management as suggested here does not preclude the use of alternative avenues for consumer redress. The only way for a firm to encourage dissatisfied consumers to voice their complaints directly to the company, and possibly change their preference for other dissatisfaction responses, is to enhance the attractiveness of the firm's own system for providing redress by (1) lowering the consumer's cost for utilizing it, and (2) increasing the quality of the remedies offered. 


\section{REFERENCES}

1. Anderson, Rolph E., "Consumer Dissatisfaction: The Effect of Disconfirmed Expectancy on Perceived Product Performance," Journal of Marketing Research, Vol. 10, February 1973, pp. 30-44.

2. Andreasen, Alan R., "A Taxonomy of Consumer Satisfaction/Dissatisfaction Measures," in H. Keith Hunt, ed., Conceptualization and Measurement of Consumer Satisfaction and Dissatisfaction, Cambridge, Marketing Science Institute, 1977, pp. 11-35.

3. Best, Arthur and Alan R. Andreasen, "Consumer Response to Unsatisfactory Purchases: A Survey of Perceiving Defects, Voicing Complaints, and Obtaining Redress," Law \& Society, Vol. 11, Spring 1977, pp. 701-742.

4. Blum, L. M., J. B. Stewart, and E. W. Wheatley, "Consumer Affairs: Viability of the Corporate Response," Journal of Marketing, Vol. 38, April 1974, pp. 13-14.

5. Crozier, Michel, The Bureaucratic Phenomenon, Chicago: University of Chicago Press, 1964.

6. Day, Ralph L., "Toward a Process Model of Consumer Satisfaction," in H. Keith Hunt, ed., Conceptualization and Measurement of Consumer Satisfaction and Dissatisfaction, Cambridge: Marketing Science Institute, 1977, pp. 153-183.

7. __ and M. Bodur, "Consumer Response to Dissatisfaction with Services and Intangibles," in H. Keith Hunt, ed., Advances in Consumer Research, Vol. V, Ann Arbor: Association for Consumer Research, 1978, pp. 263-272.

8. ___ , and E. L. Landon, Jr., "Collecting Comprehensive Consumer Complaint Data by Survey Research," in B. B. Anderson, ed., Advances in Consumer Research, Vol. III, Chicago: Association for Consumer Research, 1976.

9. Diamond, Steven L., S. Ward, and R. Faber, "Consumer Problems and Consumerism: Analysis of Calls to a Consumer Hot Line," Journal of Marketing, January 1976, pp. 5862.

10. Fornell, Claes, Consumer Input for Marketing Decisions-A Study of Corporate Departments for Consumer Affairs, New York: Praeger, 1976.

11. _ "Corporate Consumer Affairs Departments-A Communication Perspective," Journal of Consumer Policy, Vol. 2, No. 4, 1978, pp. 289-302.

12. Hannigan, John A., "The Newspaper Ombudsman and Consumer Complaints: An Empirical Assessment," Law \& Society, Vol. 11, Spring 1977, pp. 679-699.

13. Hickson, D. J., C. R. Hinings, C. A. Lee, R. E. Schneck, and J. M. Pennings, "A Strategic Contingencies Theory of Intraorganizational Power," Administrative Science Quarterly, 16, 1971, pp. 216-229.

14. Hise, Richard T., P. L. Gillette, and J. P. Kelly, "The Corporate Consumer Affairs Effort," MSU Business Topics, Summer 1978, pp. 17-26.

15. Howard, John A., Consumer Behavior: Application of Theory, New York: McGraw-Hill, Inc., 1977.

16. Jones, Mary Gardiner, "The Consumer Affairs Office-Essential Element in Corporate Policy and Planning," California Management Review, Vol. II, No. 4, Summer 1978, pp. 63-73.

17. Kendall, C. L. and F. A. Russ, "Warranty and Complaint Policies: An Opportunity for Marketing Management," Journal of Marketing, Vol. 39, April 1975, pp. 36-43.

18. Landon, E. Laird, Jr., "A Model of Consumer Complaint Behavior," paper presented at the Research Symposium on Consumer Satisfaction/Dissatisfaction and Complaining Behavior, Indiana University, Bloomington, April 20-22, 1977.

19. Lingoes, J. C. and M. Pfaff, "The Index of Consumer Satisfaction: Methodology," in M. Venkatesen, ed., Advances in Consumer Research, Iowa City: Association for Consumer Research, 1972, pp. 689-712. 
20. Mason, B. J. and S. H. Hines, Ir., "An Exploratory Behavioral and Socio-economic Profile of Consumer Action About Dissatisfaction and Selected Household Appliances," Journal of Consumer Affairs, Winter 1973, pp. 121-127.

21. McGuire, E. P., The Consumer Affairs Department: Organization and Functions, New York: The Conference Board, 1973.

22. The Nielsen Researcher, No. 1, 1974, A.C. Nielsen Company, Northbrook, lll.

23. Olshavsky, Richard W. and J. A. Miller, "Consumer Expectations, Product Performance, and Perceived Product Quality," Journal of Marketing Research, Vol. 9, February 1972, pp. 19-21.

24. Olson, Jerry C. and Philip A. Dover, "Disconfirmation of Consumer Expectation Through Product Trial," working series in Marketing Research, No. 52, December 1976, College of Business Administration, The Pennsylvania State University.

25. Pickle, H. B. and R. Bruce, "Consumerism, Product Satisfaction/Dissatisfaction: An Empirical Investigation," Southern Journal of Business, November 1972, pp. 87-100.

26. Renoux, Yves, Monsieur ou Madame Consommateur Dans L'Enterprise Pourquoi et Comment Creer un Service Consommateur, Strasbourg: Iserco, 1977.

27. Salancik, Gerald R. and Jeffrey Pfeffer, "The Bases and Use of Power in Organizational Decision Making: The Case of a University,'” Administrative Science Quarterly, 19, 1974, pp. 453-73.

28. Steele, Eric H., "Two Approaches to Contemporary Dispute Behavior and Consumer Problems," Law \& Society, Vol. 11, Spring 1977, pp. 667-675.

29. Stokes, Raymond C., "Consumer Complaints and Consumer Dissatisfaction," paper presented to the Food and Drug Law Institute, Phoenix, 1974.

30. Swan, John E. and Douglas S. Longman, "Consumer Satisfaction and Automobile Repair Performance: Attitudes Toward the Industry and Governmental Control," Proceedings, Fall Conference of the American Marketing Association, 1972, pp. 249-255.

31. Thompson, James D., Organizations in Action, New York: McGraw-Hill, 1967.

32. Warland, Rex H., Robert O. Herrmann, and J. Tillits, "Dissatisfied Consumers: Who Gets Upset and Who Takes Action?," Journal of Consumer Affairs, Vol. 9, Winter 1975, pp. 148-163. 